\title{
ANALISIS KARAKTERISTIK PERMUKIMAN DESA-DESA PESISIR DI KABUPATEN KULONPROGO
}

\author{
Djaka Marwasta \\ Fakultas Geografi Universitas Gadjah Mada, Bulaksumur, \\ Telp (0274) 902337, Fax (0274) 589595 \\ E-mail: marwasta_d@hotmail.com
}

\section{Kuswaji Dwi Priyono}

Fakultas Geografi Universitas Muhammadiyah Surakarta

Jl. A Yani Pabelan Kartosuro Tromol Pos I Surakarta 57162, Telp (0271) 717417

PS. 151-153, Fax: (0271) 715448

E-mail: kuswaji_dwip@ums.ac.id

\begin{abstract}
Cettlement is the most important area in the activity of disaster mitigation. The Biggest detriment caused by disaster is generally placed at the settlement or residential area. Thereby, the identification of the settlement characteristics is required to be able to recognize the disaster risk. This research aim to identify the characteristics of the rural settlement on the coastal area in the District of Kulonprogo. This area is chosen based on the consideration of coastal morphological characters. This area have slopeslightly coastal zone which face to Indonesian Ocean. In this situation, bence in the event of tidal wave, there will be wide spread overflowing run up water. Two approaches is used in this research, they are; (1) Morphological Approach, and (2) Behaviour Approach. Both of the approaches is conducted with comparative perspective. The existance of the settlement which have been filtered through settlement and coastal tipology are compared. The data are collected and analyzed through: (1) Mapping and GIS tools; (2) survey method; (3) Indepth interview; and (4) statistical analysis. Thirty household are selected proportionally to setlement unit as a respondent in indepth interview. In order to analyze the data, descriptive analysis (frequency tables) and crossed tables are used. This research indicate that rural settlements on the coastal area in the District of Kulonprogo are spatialy distributed as a ribbon pattern. This pattern are coincident with the shape of the coast and the linearity of the road as well. Most of the buildings are in good condition, and they characterized by moderate housing density. In the term of coastal morphology, the research area is dominated by sandy coast with slopeslightly relief. Generally, the socio economic condition of the peoples living there are low to medium economic level, low education, and rarely medium income. Related to tidal flood vulnerability, this research area is the second level (moderate) hazardeous zone.
\end{abstract}

Keywords: rural settlement, coastal area, vulnerability, disaster mitigation

\section{PENDAHULUAN}

Kejadian bencana gempa bumi yang diikuti tsunami di Aceh, Nias, Pangandaran, serta beberapa bagian wilayah Indonesia telah menyadarkan sebagian besar penduduk Indonesia akan resiko bencana di kawasan pesisir dan pantai. Banyak sekali fenomena yang menunjukkan bahwa penduduk di daerah pesisir mengalami "trauma" atau "pobhia" terhadap kejadian gempa dan tsunami. Fenomena ini menunjukkan bahwa perlu adanya sosialisasi mengenai tingkat bahaya yang mungkin terjadi di daerah-daerah permukiman di sepanjang pantai dan pesisir, terutama pada pantai 
yang berhadapan langsung dengan zona tumbukan lempeng tektonik.

Permukiman merupakan daerah yang paling penting dalam kegiatan mitigasi bencana alam, karena merupakan tempat tinggal dan tempat berkumpulnya penduduk (Katayama, 2000). Kerugian terbesar akibat bencana umumnya terdapat pada daerah permukiman penduduk. Dengan demikian identifikasi karakteristik permukiman perlu dilakukan untuk dapat mengenali tingkat resiko bencana yang mungkin terjadi.

Secara umum penelitian ini bertujuan untuk mengidentifikasi karaktersitik permukiman desa-desa pesisir sepanjang Pantai Selatan Jawa di Kabupaten Kulonprogo. Pemilihan Kabupaten Kulonprogo sebagai daerah penelitian didasari pertimbangan bahwa di Kabupaten ini memiliki pantai yang berhadapan dengan Samudera Indonesia dan umumnya morfologi pantainya cenderung landai. Sebagaimana diketahui bahwa di Samudera Indonesia terdapat pertemuan lempeng tektonik Australia dan Euro-Asia sehingga kemungkinan terjadinya tsunami relatif besar. Dengan morfologi pantai yang landai, maka apabila terjadi gelombang pasang menyebabkan air akan masuk ke daratan relatif jauh sehingga daerah luapan airnya sangat luas.

Obyek penelitian ini ialah karakteristik permukiman, lingkungan fisik, dan kondisi sosial ekonomi desa pesisir. Lokasi Penelitian adalah desa-desa yang memiliki pantai di Samudera Indonesia yang termasuk dalam Wilayah Kabupaten Kulonprogo. Secara umum penelitian ini bertujuan untuk: (1) mengidentifikasi karakteristik permukiman, kondisi sosial- ekonomi dan fisik lingkungan permukiman desa-desa pesisir sepanjang Pantai Selatan Jawa di Kabupaten Kulonprogo; (2) mengkaji keterkaitan antara karakteristik permukiman dengan kondisi sosial-ekonomi dan fisik lingkungan permukiman desa-desa pesisir sepanjang Pantai Selatan Jawa di Kabupaten Kulonprogo; serta (3) pemintakatan bahaya bencana gelombang pasang..

\section{METODE PENELITIAN}

Secara umum penelitian bersifat deskriptif-evaluatif dengan menggunakan dua pendekatan yaitu pendekatan Morphological Approach dan Behaviour Approach (Neer, 1999). Pendekatan pertama berkaitan dengan kajian aspek setting geografis dan lingkungan dari eksistensi dan karakteristik permukiman. Pendekatan kedua berkaitan dengan kajian proses memukimi oleh penduduk, "survival strategy" yang dimiliki oleh penduduk yang dimanifestasikan dalam kondisi sosio-ekonomiknya. Kedua pendekatan tersebut dioperasionalisasikan dengan comparative perspective, yaitu dengan membandingkan eksistensi permukiman yang disaring melalui mekanisme penentuan tipologi permukiman dan tipologi pantai

Data yang digunakan dalam penelitian ini diperoleh dari interpretasi citra Landsat ETM tahun 2004 (http:// www.Landsat.org) (http://www.usgs.gov/ pubprod/satellitedata), peta-peta tematik, data PODES 2005, dan hasil wawancara terhadap responden secara indepth interview. Untuk penentuan responden di dalam kegiatan indepth interview digunakan teknik quota sampling. Sebanyak $30 \mathrm{KK}$ diambil sebagai responden, dimana masingmasing desa diwakili oleh 3 orang kepala rumah tangga sebagai responden. Pemilihan responden dilakukan secara acak 
untuk masing-masing desa, dan orang yang dijadikan responden adalah kepala keluarga. Analisis data dilakukan dengan menggunakan perangkat lunak SIG berbasis vektor (Arcview versi 3.3) dan raster (ENVI versi 4.0), dan perangkat lunak analisis statistik SPSS versi 12 . Teknik analisis yang digunakan adalah analisis spasial dan analisis statistik deskriptif (tabel frekuensi maupun tabel silang).

Dalam studi ini, digunakan unit analisis desa pesisir. Obyek yang dikaji pada masing-masing unit analisis adalah: (1) karakteristik permukiman meliputi: (a) pola sebaran permukiman; (b) kepadatan permukiman; dan (c) permanensi bangunan; (2) karakteristik sosial ekonomi penduduk meliputi: (a) jenis pekerjaan; (b) tingkat ekonomi; dan (c) tingkat pendidikan; (3) karaktersitik fisik lingkungan meliputi: (a) morfologi pantai; (b) bentuk lahan; dan (c) aksesibilitas fisik.

Hasil identifikasi karakterisitik permukiman dan kondisi sosio-ekonomi diwujudkan dalam bentuk peta karakteristik permukiman dan kondisi sosio-ekonomi penduduk daerah penelitian. Disamping itu juga dilakukan pemetaan kondisi fisik lingkungan daerah penelitian, yang didasarkan pada interpretasi citra Landsat ETM maupun peta hasil penelitian/publikasi dan atau turunan dari peta Rupa Bumi Indonesia. Keseluruhan peta selanjutnya dianalisis dengan SIG untuk menghasilkan model keterkaitan antar faktor. Dari hasil analisis SIG selanjutnya dianalisis secara statistik (analisis frekuensi dan tabel silang). Dari hasil analisis SIG juga dapat diturunkan output penelitian berupa pemintakatan bahaya bencana gelombang pasang daerah permukiman di desa-desa pesisir dengan teknik overlay dan model iterasi sederhana.

\section{HASIL DAN PEMBAHASAN}

Secara adminstratif daerah penelitian meliputi 10 desa dari 4 kecamatan. Desadesa tersebut meliputi Jangkaran, Sindutan, Palihan dan Glagah yang termasuk wilayah administrasi Kecamatan Temon. Desa Karang Wuni termasuk wilayah administrasi Kecamatan Wates, sedangkan Desa Garongan, Pleret, dan Bugel, termasuk wilayah Kecamatan Panjatan, serta Karangsewu dan Banaran termasuk wilayah Kecamatan Galur.

Secara geomorfologis, berdasarkan asal proses utamanya, fenomena bentanglahan di daerah penelitian dapat dikelompokkan ke dalam 2 satuan geomorfologi, yaitu: satuan geomorfologi asal proses marin dan asal proses eolian (lihat Gambar 1). Satuan gemorfologi yang terbentuk akibat proses marin (aktivitas gelombang laut) yang ada di daerah penelitian dapat dikelompokkan menjadi 2, yaitu satuan gisik (beach) dan beting gisik (beting gisik). Gisik di daerah penelitian merupakan zona yang relatif sempit di sepanjang pantai, dengan lebar antara 25 hingga 50 meter, secara spesifik berada di sekitar muara Sungai Serang.

Satuan geomorfologi asal proses aktivitas angin (eolian) adalah gumuk pasir (sand dunes). Di daerah penelitian kompleks gumuk pasir ini berselang-seling dengan Swale, yaitu suatu bentanglahan yang berupa cekungan di antara dua gumuk pasir, yang dapat berperan sebagai ledok drainase. Kompleks gumuk pasir dan swale secara keseluruhan membentuk relief berombak yang tersusun oleh material pasir lepas. Pada dasar swale, biasanya dijumpai akumulasi material yang lebih halus seperti lempung dan debu, yang memungkinkan lahan ini 


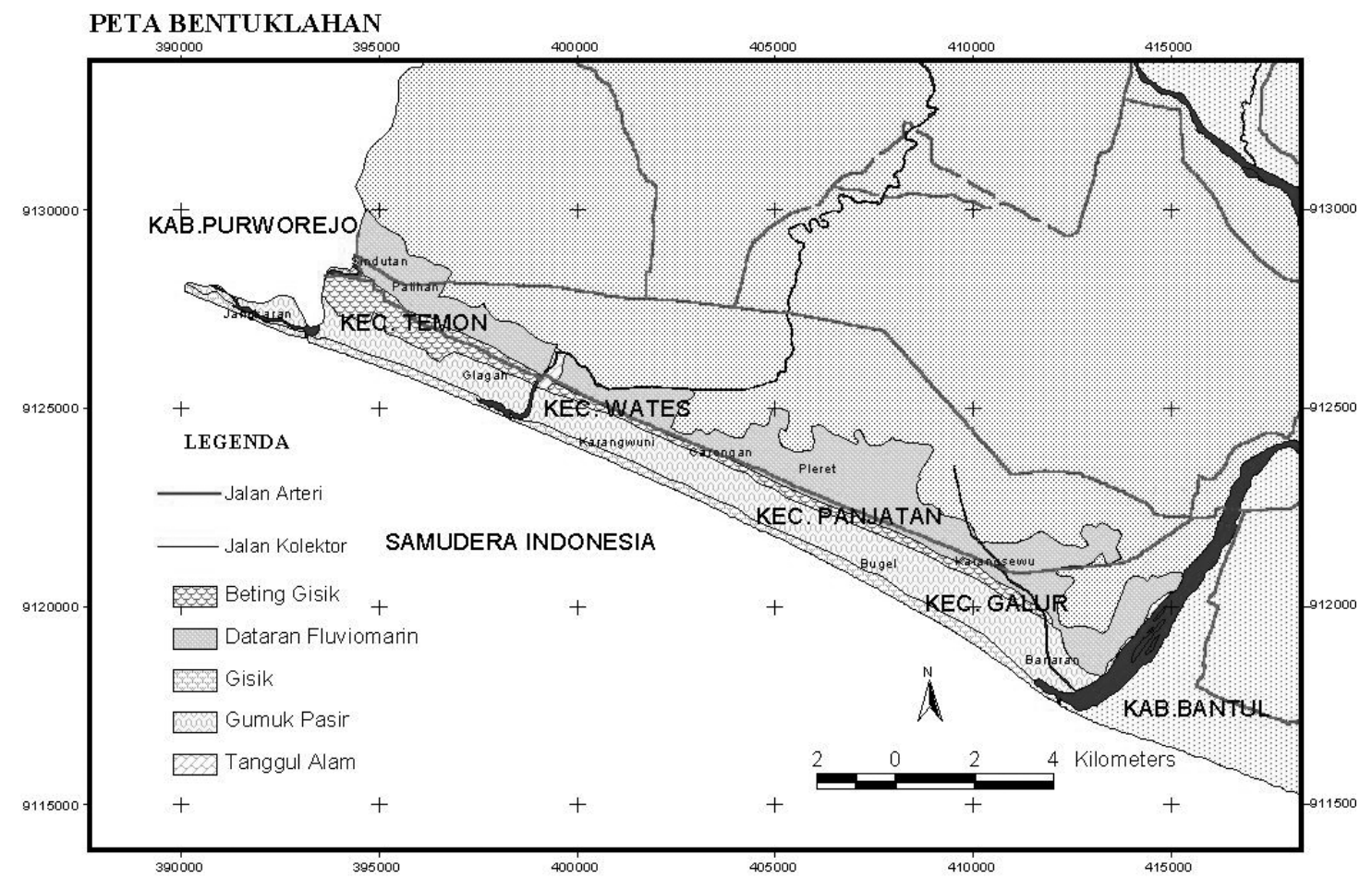

Gambar 1. Peta Bentuklahan Daerah Penelitian

dapat dimanfaatkan sebagai lahan pertanian tanaman semusim, seperti: cabe, tomat, terong, sawi, atau jenis polowijo lainnya. Jenis penggunaan lahan ini bertahan sepanjang tahun, karena ketersediaan airtanah yang cukup, relatif dangkal, dan rasanya tawar, di seluruh kompleks gumuk pasir dan swale.

Secara umum permukiman di daerah penelitian berlokasi di bagian bentuklahan beting gisik dan dataran fluviomarin. Kondisi tersebut merupakan manifestasi dari adaptasi penduduk terhadap lingkungan di dalam menentukan lokasi tempat hunian (Yunus, 1989). Proses memukimi daerahdaerah tersebut didasari pertimbangan bahwa pada daerah beting gisik secara topografis letaknya lebih tinggi dibandingkan daerah di sekitarnya, sedangkan pemilihan di dataran fluvio marin didasari oleh kede- katannya terhadap lahan-lahan yang dapat diusahakan untuk aktivitas pertanian padi sawah. Letak yang lebih tinggi memberikan keuntungan terhindar dari pengaruh banjir yang sering terjadi terutama di daerah sekitar muara sungai, maupun relatif aman dari aktivitas pasang surut air laut.

Secara umum pola sebaran permukiman di daerah permukiman adalah mengelompok dengan bentuk memanjang sepanjang pantai, berarah timur ke barat (lihat Gambar 2). Hal ini bisa dimaklumi karena bentuk beting gisik umumnya memang selaras dengan garis pantai. Hanya di beberapa tempat di dataran fluvio marin pola permukiman penduduknya mengelompok berbentuk segi empat, dan beberapa kelompok permukiman memanjang sejajar jalan arah utara-selatan, terutama rumah-rumah yang dibangun setelah terbangun- 
nya jalan-jalan penghubung jalur selatan dan jalur tengah Kabupaten Kulonprogo.

Kepadatan permukiman desa-desa pesisir umumnya tinggi, terutama pada desa-desa nelayan, tetapi fenomena desadesa pesisir di Kabupaten Kulonprogo menunjukkan bahwa kepadatan permukimannya relatif rendah. Secara umum kepadatan penduduk pada daerah permukiman kurang dari 200 jiwa setiap hektarnya. Hanya Desa Karang Sewu yang memiliki kepadatan lebih dari 300 jiwa per hektar. Padatnya penduduk pada lahan permukiman di Desa Karang Sewu terutama disebabkan oleh pola permukimannya yang cenderung mengelompok dan asosiatif dengan lahanlahan pertanian. Aktivitas pertanian di desa ini sangat menonjol sehingga mengontrol pola dan kepadatan permukimannya.
Dari aspek kepadatan rumah mukim, rerata kepadatan rumah mukimnya cenderung tinggi (lihat Tabel 1). Semua desa memiliki kepadatan rumah mukim rerata lebih dari 20 rumah setiap hektarnya. Desa Karang Sewu yang memiliki kepadatan penduduk pada lahan permukiman tertinggi, juga merupakan desa dengan rerata kepadatan bangunan rumah tertinggi, yaitu lebih dari 60 unit rumah per hektar. Dengan angka kepadatan lebih dari 60 rumah per hektar, desa ini tergolong berkepadatan tinggi.

Ditinjau dari permanensi bangunan, secara umum proporsi antara permukiman permanen dengan non permanen di daerah penelitian cenderung seimbang. Tingkat permanensi bangunan rumah mukim dapat dijadikan sebagai tolok ukur kualitas permukiman pada umumnya (Yunus, 1989).

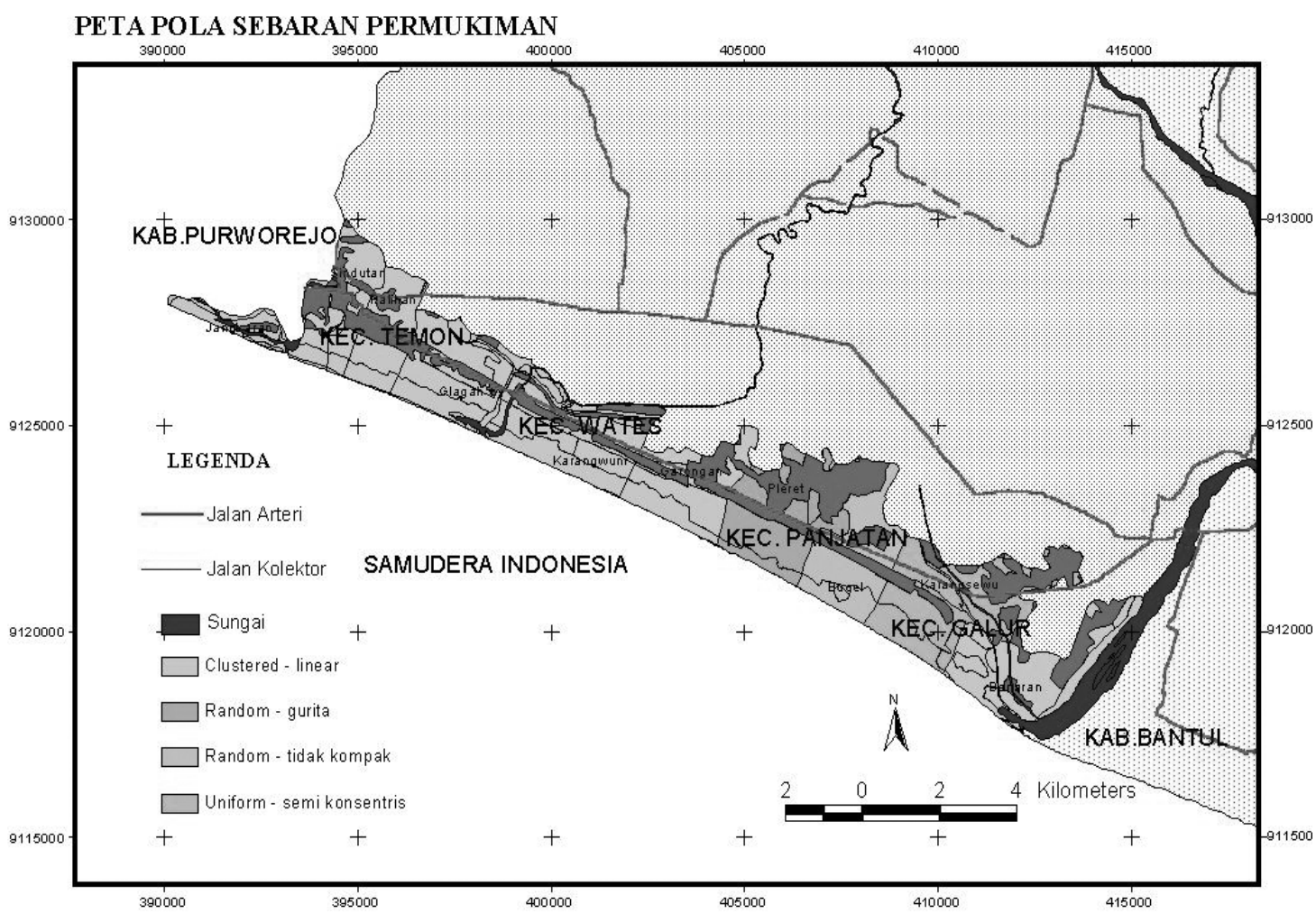

Gambar 2. Peta Pola Persebaran Permukiman Daerah Penelitian 
Tabel 1. Kepadatan dan Permanensi Rumah Mukim Menurut Desa

\begin{tabular}{|l|c|r|c|r|c|c|c|}
\hline \multicolumn{1}{|c|}{ Desa } & Rumah & Permanen & $\mathbf{\%}$ & $\begin{array}{c}\text { non } \\
\text { Permanen }\end{array}$ & $\mathbf{\%}$ & $\begin{array}{c}\text { Luas } \\
\text { Permukiman } \\
\text { (Ha) }\end{array}$ & $\begin{array}{c}\text { Kepadatan } \\
\text { (rumah/ha) }\end{array}$ \\
\hline Jangkaran & 324 & 217 & 66,98 & 107 & 33,02 & 13,8 & 23,5 \\
Sindutan & 392 & 263 & 67,09 & 129 & 32,91 & 11 & 35,6 \\
Palihan & 420 & 249 & 59,29 & 171 & 40,71 & 17,2 & 24,4 \\
Glagah & 542 & 361 & 66,61 & 181 & 33,39 & 18 & 30,1 \\
Karang Wuni & 725 & 521 & 71,86 & 204 & 28,14 & 14,4 & 50,3 \\
Garongan & 614 & 359 & 58,47 & 255 & 41,53 & 24,4 & 25,2 \\
Pleret & 777 & 285 & 36,68 & 492 & 63,32 & 31,8 & 24,4 \\
Bugel & 862 & 400 & 46,40 & 462 & 53,60 & 31,7 & 27,2 \\
Karang Sewu & 1456 & 1333 & 91,55 & 123 & 8,45 & 23,4 & 62,2 \\
Banaran & 1109 & 1075 & 96,93 & 34 & 3,07 & 49,9 & 22,2 \\
\hline \multicolumn{1}{|c|}{ Jumlah } & $\mathbf{7 2 2 1}$ & $\mathbf{5 0 6 3}$ & $\mathbf{7 0 , 1 1}$ & $\mathbf{2 1 5 8}$ & $\mathbf{2 9 , 8 9}$ & $\mathbf{2 3 5 , 6}$ & $\mathbf{3 0 , 6}$ \\
\hline
\end{tabular}

Sumber: Hasil Pengolahan Data PODES tahun 2003 dan Hasil Analisis dengan SIG

Semakin banyak bangunan non permanen mengindikasikan semakin rendahnya kualitas permukiman. Persentase bangunan permanen di semua desa yang diteliti adalah $70 \%$ yang menunjukkan bahwa secara umum kualitas permukiman di daerah penelitian tergolong cukup baik. Desa Banaran merupakan desa yang memiliki kualitas permukiman terbaik di antara desa lainnya, sedangkan Desa Pleret merupakan desa dengan kualitas permukiman terendah.

Kondisi fisik lingkungan merupakan faktor penting dalam proses memukimi maupun produk yang berupa permukiman (Bockstael, 1996). Pola persebaran permukiman rural lebih banyak ditentukan oleh faktor fisik lingkungan dibandingkan pertimbangan-pertimbangan sosio-ekonomik semata (Knox,2004) (Hardie,1997). Dalam hal permukiman di daerah pesisir, kondisi fisik yang secara signifikan berpengaruh terhadap terbentuknya pola persebaran permukiman tertentu adalah morfologi pantai, bentuk lahan, dan aksesibilitas fisik.

Secara morfologis daerah penelitian termasuk ke dalam tipe pantai berpasir, dimana aktivitas yang dominan adalah proses sedimentasi material gunungapi yang terbawa oleh air sungai (dalam hal ini sungai Progo, Serang, dan Bogowonto), maupun aktivitas pasang surut air laut. Ciri morfologis pantainya adalah berlereng cenderung landai, banyak dijumpai gumuk pasir (sand dunes), bermaterial pasir lepas, dan garis pantainya cenderung lurus dan panjang.

Di kanan-kiri aliran sungai di daerah penelitian dapat dijumpai satuan bentuklahan tanggul alam. Tanggul alam di daerah penelitian dapat dikelompokkan menjadi 2, yaitu: tanggul alam muda (F2) yang ada di sekitar aliran Sungai Serang, dan tanggul alam tua (F3). Tanggul alam muda terbentuk akibat aktivitas Sungai Serang, yang kemungkinan akan terus berkembang selama sungai ini tetap mengalir sepanjang tahun, pada saat ini dimanfaatkan oleh 
penduduk untuk tegalan dan perkebunan. Tanggul alam tua pada saat ini telah dimanfaatkan sebagai lahan permukiman penduduk atau pekarangan dengan budidaya tanaman semusim (polowijo dan buahbuahan).

Satuan Dataran Fluviomarin yang ada di daerah penelitian merupakan satuan geomorfologi yang terbentuk sebagai hasil kerjasama aktivitas marin berupa laguna dengan aktivitas sedimentasi. Akibat proses sedimentasi dari daratan, maka laguna ini tertutup dan menjadi daratan, atau akibat aktivitas manusia, genangan ini kemudian diatuskan sehingga dapat kering dan dapat dijadikan lahan pertanian. Mengingat satuan ini secara genesis bekas laguna yang dulunya tergenang sepanjang tahun, maka drainase permukaannya buruk. Kondisi yang demikian menyebabkan pada satuan ini banyak dimanfaatkan untuk pertanian lahan basah. Karena topografinya yang rendah dan lebih mudah tergenang air, maka "sistem surjan" diterapkan sebagai pola tanam sepanjang tahun pada satuan ini, dimana pada bagian bawah (alur-alurnya) ditanami padi, sedang pada bagian atas (guludan) ditanami cabe atau jenis polowijo lainnya. Kondisi sekarang banyak dibuat sumur-sumur pantek sebagai sumber irigasi di musim kemarau.

Satuan Beting Gisik tua dimanfaatkan sebagai lahan permukiman. Beting gisik di daerah penelitian umumnya hanya bersifat tunggal atau satu jalur. Satuan ini mempunyai topografi yang relatif datar atau sedikit berombak, relief teratur, dan didominasi oleh material pasir dengan ukuran halus bercampur dengan sedikit debu dan lempung pada bagian atas. Kondisi ini menyebabkan akuifer pada satuan ini cukup baik, airtanah dangkal dan berasa tawar, sehingga banyak dimanfaatkan oleh penduduk sebagai sumber air bersih, yaitu dengan membuat sumur-sumur gali biasa atau dengan sumur pompa. Pada satuan ini banyak dimanfaatkan sebagai lahan permukiman dan pekarangan dengan berbagai jenis tanaman perkebunan, buah-buahan dan polowijo.

Karakteristik sosial ekonomi penduduk di daerah penelitian dapat ditelaah berdasarkan jenis pekerjaan, tingkat ekonomi, dan tingkat pendidikan. Menurut jenis pekerjaan utama kepala keluarga, hampir semua desa didominasi jenis pekerjaan agraris (lihat Tabel 2), baik sebagai petani pemilik, petani penggarap, maupun buruh tani. Jelaslah bahwa budaya agraris masih mendominasi pada setiap aktivitas penduduknya. Sebagai desa pesisir, ternyata budaya maritim belum merambah sendi-sendi kehidupan masyarakatnya. Kehidupan penduduk masih lebih dominan ditopang dari sektor pertanian darat, belum banyak dijumpai penduduk yang bekerja sebagai nelayan meskipun rumahnya dekat dengan laut. Bahkan ironisnya, kalaupun ada nelayan adalah pendatang dari daerah lain, misalnya dari Cilacap.

Tingkat ekonomi penduduk dapat diukur dengan berbagai pendekatan, misalnya pendapatan kepala keluarga, konsumsi rumah tangga, pendapatan per kapita, dan sebagainya. Dalam penelitian ini digunakan persentase rumah tangga miskin. Tingkat ekonomi penduduk di daerah penelitian umumnya tergolong tingkat ekonomi cukup. Ditinjau dari kategorisasi rumah tangga miskin, umumnya desa-desa di daerah penelitian memiliki rumah tangga miskin kurang dari 3\%, kecuali di desa Karang Wuni yang hampir mencapai 5\% (lihat Tabel 2). 
Tabel 2. Keluarga Miskin, Jenis Pekerjaan Utama Kepala Keluarga, dan Keluarga dengan Anggota Rumah Tangga Berpendidikan Tinggi menurut Desa

\begin{tabular}{|c|c|c|c|c|c|c|c|c|c|c|}
\hline Desa & $\begin{array}{l}\text { Jumlah } \\
\text { Penduduk }\end{array}$ & $\begin{array}{c}\text { Jumlah } \\
\text { KK }\end{array}$ & $\begin{array}{c}\text { KK } \\
\text { Miskin }\end{array}$ & $\%$ & $\begin{array}{c}\text { KK } \\
\text { Pertanian }\end{array}$ & $\%$ & \begin{tabular}{|c|} 
KK \\
non \\
Pertanian
\end{tabular} & $\%$ & $\begin{array}{l}\text { KK dengan } \\
\text { ART di PT }\end{array}$ & $\%$ \\
\hline Jangkaran & 1735 & 322 & 9 & 2,80 & 258 & 80,12 & 64 & 19,88 & 8 & 2,48 \\
\hline Sindutan & 2012 & 489 & 5 & 1,02 & 429 & 87,73 & 60 & 12,27 & 11 & 2,25 \\
\hline Palihan & 2433 & 466 & 5 & 1,07 & 265 & 56,87 & 201 & 43,13 & 10 & 2,15 \\
\hline Glagah & 2680 & 578 & 5 & 0,87 & 346 & 59,86 & 232 & 40,14 & 16 & 2,77 \\
\hline Karang Wuni & 2794 & 704 & 35 & 4,97 & 598 & 84,94 & 106 & 15,06 & 45 & 6,39 \\
\hline Garongan & 3388 & 772 & 3 & 0,39 & 676 & 87,56 & 96 & 12,44 & 32 & 4,15 \\
\hline Pleret & 4925 & 898 & 5 & 0,56 & 741 & 82,52 & 157 & 17,48 & 73 & 8,13 \\
\hline Bugel & 4442 & 917 & 4 & 0,44 & 876 & 95,53 & 41 & 4,47 & 67 & 7,31 \\
\hline Karang Sewu & 7506 & 1586 & 25 & 1,58 & 1110 & 69,99 & 476 & 30,01 & 237 & 14,94 \\
\hline Banaran & 5330 & 1131 & 7 & 0,62 & 791 & 69,94 & 340 & 30,06 & 42 & 3,71 \\
\hline Jumlah & 37245 & 7863 & 103 & 1,31 & 6090 & 77,45 & 1773 & 22,55 & 541 & 1,31 \\
\hline
\end{tabular}

Sumber: Hasil Pengolahan Data PODES tahun 2003

Pendidikan merupakan salah satu parameter yang banyak digunakan untuk menilai kondisi sosial ekonomi penduduk. Salah satu tolok ukur untuk menentukan tingkat pendidikan penduduk adalah dengan melihat persentase keluarga yang memiliki anggota rumah tangga berpendidikan perguruan tinggi. Dengan adanya anggota rumah tangga berpendidikan tinggi akan berdampak pada pola pikir dan pola tindak di dalam keluarga.

Diukur berdasarkan persentase keluarga dengan anggota rumah tangga berpendidikan perguruan tinggi, Desa Karang Sewu merupakan desa dengan tingkat pendidikan tertinggi dibanding desa-desa lain (lihat Tabel 2). Jumlah keluarga yang memiliki anggota rumah tangga berpendidikan tinggi membawa dampak pada tingkat kemajuan sosial dan ekonomi masyarakat secara umum. Karang Sewu, walaupun secara umum tergolong desa miskin, tetapi memiliki kemajuan dalam bidang pendidikan.
Dapat disimpulkan bahwa secara umum kondisi sosial ekonomi di daerah penelitian masih didominasi sektor pertanian tanaman pangan, tingkat ekonomi masyarakat umumnya miskin hingga cukup, dan tingkat pendidikan relatif rendah. Budaya maritim belum banyak menyentuh sistem kegiatan keseharian penduduk walaupun mereka tinggal di daerah pesisir yang memiliki sumberdaya kelautan yang masih melimpah. Dampak terhadap mitigasi kebencanaan daerah pesisir adalah bahwa sense penduduk terhadap bencana akibat aktivitas laut masih tergolong rendah. Seperti yang pernah terjadi beberapa waktu yang lalu tentang kemungkinan terjadinya badai tropis di Pantai Selatan Jawa, ternyata malah disikapi dengan cara-cara dan budaya agraris yaitu makan sayur tujuh macam.

Karakteristik permukiman penduduk yang bercirikan bentuk memanjang dengan pola mengelompok (clustered), berkepadatan tinggi, dan proporsi bangunan permanen seimbang dengan bangunan non permanen, berhubungan dengan kondisi fisik ling- 
kungan maupun kondisi sosial ekonomi penduduk. Terbentuknya pola persebaran permukiman tertentu dipengaruhi oleh faktor internal penghuni yang berkait erat dengan kondisi sosial ekonomi penduduk, serta faktor eksternal yang didominasi oleh faktor fisik lingkungan (Yunus, 1989) (Gustafson, 1998). Pada setiap lokasi geografis tertentu memiliki kondisi fisik lingkungan dan kondisi sosial ekonomi masyarakat yang berbeda-beda, sehingga determinan terbentuknya pola persebaran permukiman pada masing-masing tempat juga berbeda-beda (Fajita, 1982).

Hubungan antara karakteristik sosial ekonomi penduduk dengan karakteristik permukiman dianalisis dengan tabel silang menggunakan data primer hasil wawancara dengan 30 responden sebagai sampel. Berdasarkan hasil analisis terhadap data yang diperoleh dengan cara wawancara dengan responden menunjukkan bahwa terdapat hubungan cukup signifikan antara karakteristik sosial ekonomi penduduk dengan karakteristik permukimannya. Permukiman Tipe A adalah permukiman berpola mengelompok, kepadatan tinggi, dan kualitas bangunan kurang baik, tipe $\mathrm{B}$ adalah permukiman berpola mengelompok dan atau random, kepadatan sedang, kualitas bangunan sedang, tipe $\mathrm{C}$ berpola random dan atau uniform, kepadatan rendah hingga sedang, dan kualitas bangunannya sedang hingga baik.

Permukiman tipe A didominasi oleh sektor pekerjaan pertanian, Tipe B oleh sektor perdagangan dan jasa, dan tipe $\mathrm{C}$ oleh PNS (lihat Tabel 3). Dapat disimpulkan bahwa sektor pekerjaan berhubungan cukup signifikan dengan karakteristik permukiman, dimana kepala keluarga yang bekerja dalam sektor pertanian umumnya kurang baik tipe permukimannya. Tingkat ekonomi keluarga juga memiliki hubungan cukup signifikan dengan tipe permukiman, dimana semakin tinggi tingkat ekonominya semakin baik tipe permukimannya (lihat Tabel 4). Secara umum tipe permukiman di daerah penelitian adalah tipe menengah, dan ini sejalan dengan tingkat ekonomi yang juga didominasi kategori sedang.

Tingkat pendidikan anggota rumah tangga juga berhubungan signifikan dengan tipe permukiman. Semakin rendah tingkat pendidikan anggota rumah tangga semakin kurang baik tipe permukimannya (lihat Tabel 5). Perlu dijelaskan bahwa variabel lokasi dan provisi permukiman tidak digunakan untuk menentukan tipe permukiman karena kedua variabel ini homogen

Tabel 3. Tipe Permukiman menurut Sektor Pekerjaan

\begin{tabular}{|c|c|c|c|c|c|c|c|}
\hline \multirow{2}{*}{ Sektor Pekerjaan } & \multicolumn{6}{|c|}{ Tipe Permukiman } & \multirow{2}{*}{ Jumlah } \\
\hline & $\mathbf{A}$ & $\%$ & B & $\%$ & $\mathrm{C}$ & $\%$ & \\
\hline Pertanian & 9 & $(82)$ & 6 & $(50)$ & 1 & (14) & 16 \\
\hline Perdagangan\&Jasa & 1 & (9) & 3 & $(25)$ & 4 & $(57)$ & 8 \\
\hline PNS & 1 & (9) & 3 & $(25)$ & 2 & $(29)$ & 6 \\
\hline Jumlah & 11 & $(100)$ & 12 & $(100)$ & 7 & $(100)$ & 30 \\
\hline
\end{tabular}

Sumber: Hasil Olahan Data Primer 2005 
Tabel 4. Tipe Permukiman menurut Tingkat Ekonomi

\begin{tabular}{|c|c|c|c|c|c|c|c|}
\hline \multirow{2}{*}{ Tingkat Ekonomi } & \multicolumn{6}{|c|}{ Tipe Permukiman } & \multirow{2}{*}{ Jumlah } \\
\hline & $\mathbf{A}$ & $\%$ & B & $\%$ & $\mathrm{C}$ & $\%$ & \\
\hline Rendah & 3 & $(27)$ & 1 & (8) & 1 & (14) & 5 \\
\hline Sedang & 6 & $(55)$ & 10 & (84) & 4 & $(57)$ & 20 \\
\hline Tinggi & 2 & $(18)$ & 1 & (8) & 2 & $(29)$ & 5 \\
\hline Jumlah & 11 & $(100)$ & 12 & $(100)$ & 7 & $(100)$ & 30 \\
\hline
\end{tabular}

Sumber: Hasil Olahan Data Primer 2005

di semua desa yang diteliti. Demikian juga dengan variabel struktur keluarga dan pola pemilikan rumah dan lahan juga tidak disertakan dalam menentukan kondisi sosial ekonomi karena keduanya juga homogen.

Secara spasial tipe permukiman pada desa-desa pesisir Pantai Selatan Jawa di Kabupaten Kulonprogo terdistribusi atas tipe permukiman A tersebar di bagian tengah, tipe permukiman $B$ menempati desa-desa di bagian barat, dan tipe permukiman $\mathrm{C}$ berada di bagian timur dari daerah penelitian (lihat gambar 2). Aksesibilitas memegang peranan di dalam pola persebaran tipe permukiman tersebut, dimana daerah timur yang lebih dekat dengan Kota Yogyakarta tipe permukimannya paling baik. Secara administratif Kabupaten Kulonprogo termasuk ke dalam propinsi DI Yogyakarta, sehingga keterikatan terhadap Kota Yogyakarta sebagai ibukota propinsi memberikan pengaruh terhadap karakteristik sosial ekonomi yang berdampak terhadap pola permukiman yang lebih baik dibandingkan bagian tengah dan barat.

Bagian tengah merupakan daerah yang paling kurang aksesibel secara kewilayahan, sedangkan bagian barat justru cenderung lebih aksesibel karena relasi ekonomi terhadap Kabupaten Purworejo relatif lebih baik dibandingkan bagian tengah. Konsekuensi dari fenomena tersebut menjadikan bagian barat tipe permukimannya cenderung lebih baik daripada bagian tengah, walaupun tidak sebaik bagian timur. Dalam hal ini ditemui kenyataan bahwa secara kualitatif aksesibilitas fisik berpengaruh cukup nyata terhadap karakteristik permukiman yang terbentuk di suatu tempat tertentu (Spellerberg, 1998).

Dalam hubungannya dengan faktor fisik lingkungan, secara visual terlihat nyata bahwa bentuk lahan sangat menentukan pola persebaran dan bentuk permukiman. Permukiman hanya dijumpai pada satuan bentuklahan beting gisik dan dataran fluviomarin, dengan karakteristik pada beting gisik berpola mengelompok dengan bentuk memanjang (linear) sejajar dengan garis pantai, dan pada dataran fluviomarin berpola random dan atau uniform dengan bentuk bintang dan atau memanjang sejajar dengan jalan. Morfologi pantai yang homogen di daerah penelitian menyebabkan hubungan antara variabel ini dengan pola permukimannya tidak tampak nyata. Hubungan morfologi pantai dengan karak-teristik permukiman akan dapat dianalisis dengan jelas apabila terdapat variasi tipe morfologi pantai untuk berbagai karakteristik permukiman. 
Tabel 5. Tipe Permukiman menurut Tingkat Pendidikan

\begin{tabular}{|c|c|c|c|c|c|c|c|}
\hline \multirow{2}{*}{ Tingkat Pendidikan } & \multicolumn{6}{|c|}{ Tipe Permukiman } & \multirow{2}{*}{ Jumlah } \\
\hline & $\mathbf{A}$ & $\%$ & B & $\%$ & $\mathrm{C}$ & $\%$ & \\
\hline Rendah & 6 & $(55)$ & 3 & $(25)$ & 1 & (14) & 10 \\
\hline Sedang & 3 & $(27)$ & 6 & $(50)$ & 2 & $(29)$ & 11 \\
\hline Tinggi & 2 & (18) & 3 & $(25)$ & 4 & $(57)$ & 9 \\
\hline Jumlah & 11 & $(100)$ & 12 & $(100)$ & 7 & $(100)$ & 30 \\
\hline
\end{tabular}

Sumber: Hasil Olahan Data Primer 2005

Salah satu faktor yang sangat perlu diperhatikan bagi permukiman-permukiman pada daerah pesisir adalah kerawanan terhadap bencana alam, terutama yang disebabkan oleh aktivitas laut, misalnya rob dan tsunami. Usaha mitigasi ataupun meminimalisasi resiko apabila terjadi bencana sangat diperlukan untuk menghindari banyaknya korban bencana, salah satu caranya adalah dengan melakukan pemintakatan tingkat bahaya bencana untuk daerah-daerah di sepanjang pantai dan pesisir. Dalam penelitian ini analisis deskriptif kualitatif digunakan untuk menakar tingkat bahaya masing-masing desa di daerah penelitian. Dari faktor fisik jelas bahwa semua desa memiliki tingkat bahaya yang hampir sama, karena umumnya penduduk menghuni di satuan bentuklahan beting gisik yang memiliki ketinggian relatif rendah terhadap muka air laut. Keberadaan gumuk pasir juga kurang membantu karena volumenya yang relatif kecil. Dengan bentuk permukiman yang memanjang sepanjang pantai, resiko terkena gelombang pasang semua desa tersebut relatif tinggi.

Namun demikian, ada dua hal yang cukup memberikan pengaruh positif terhadap rendahnya kerentanan terhadap bencana, yaitu kepadatan penduduk dan aksesibilitas untuk mencapai daerah atas.
Penentuan tingkat resiko ini hanya didasarkan pada jumlah penduduk, kepadatan rumah mukim, dan kepadatan jalan. Secara umum tingkat resiko bencana tsunami di desa-desa pesisir tersebut terdistribusi secara acak, tidak menunjukkan pola atau konsistensi ruang tertentu. Namun demi-kian secara umum tingkatnya adalah sedang.

\section{KESIMPULAN DAN SARAN}

\section{Kesimpulan}

1. Karakteristik permukiman desa-desa pesisir sepanjang Pantai Selatan Jawa di Kabupaten Kulonprogo menunjukkan pola mengelompok (clustered) berbentuk linear sejajar garis pantai, kepadatan rumah sedang, terletak pada satuan bentuklahan beting gisik, tipe morfologi pantai berpasir, lereng landai, aksesibilitas fisik baik, ditandai kepadatan jalan tinggi, serta kondisi sosial ekonomi penduduk kategori menengah, dicirikan oleh pekerjaan sektor pertanian, tingkat ekonomi sedang, tingkat pendidikan sedang.

2. karakteristik permukiman berhubungan secara signifikan dengan kondisi sosial ekonomi penduduk dan kondisi fisik lingkungan permukiman, dimana semakin tinggi kondisi sosial ekonomi 
semakin baik tipe permukimannya.

3. secara umum tingkat bahaya terhadap bencana gelombang pasang di daerah penelitian berada pada tingkat sedang.

\section{Saran}

Perlu dilakukan sosialisasi kepada ma-syarakat pesisir selatan di Kabupaten
Kulonprogo mengenai mitigasi bencana gelombang pasang maupun tsunami secara intensif, mengingat masyarakat setempat kurang memiliki sense of hazard terhadap potensi bencana tersebut. Demikian pula kebijakan tata ruang daerah pesisir perlu dirumuskan secara sungguh-sungguh untuk mengurangi resiko bencana yang mungkin terjadi pada kawasan itu.

\section{DAFTAR PUSTAKA}

Bockstael, N. E. 1996. "Modeling Economics and Ecology: The Importance of a Spatial Perspective." American Journal of Agricultural Eronomics 78 (December): 168-80.

Fajita, M. 1982. "Spatial Patterns of Residential Development, Journal of Urban Economics $12: 22-52$.

Gustafson, E. J. 1998. Quantifying Landscape Spatial Pattern: What is the state of the art? Ecosystems 1:143-156.

Hardie, I.W., and P.J. Parks. 1997. "Land Use with Heterogeneous Land Quality: An Application of an Area Base Mode." American Joumal of Agricultural Economics 79 (May): 299-3 10.

Katayama, Ritsu et al., 2000, A Research On The Urban Disaster Prevention Plan Concerning Earthquake Risk Forecast By Remoto Sensing in The Tokyo Bay Area, ISPRS, Vol, Part B7, P6 62-669, Amsterdam.

Knox, Paul, and Marston, Sallie, 2004, Human Geography: Places and Regions in Global Context. Third Edition, Upper Saddle River, N.J.: Prentice Hall.

Landsat. http://www.landsat.org (accessed 11 Febr. 2005)

Neer, J. T., 1999. High Resolution Imaging from Space - A Commercial Perspective on a Changing Landscape, International Archives of Photogrammetry and Remote Sensing, XXXII (7C2): $p$ p. 132-143.

Ritohardoyo, S. dan Priyono. 2005. "Perkembangan Permukiman dan Perubahan Daya Dukung Lingkungan Perdesaan Daerah Aliran Sungai Progo". Forum Geografi, Vol. 19, No. 2, Desember 2006. Hlm 127-141.

Spellerberg, I.F., 1998. Ecological Effects of Roads and Traffic: a Literature Review. Global Ecology and Biogeography 7: 317-333.

USGS. http://www.usgs.gov/pubprod/satellitedata.html (accessed 14 Febr. 2005)

Yunus, H. S. 1989. Subject Matter dan Metode Penelitian Geografi Permukiman Kota. Fakultas Geografi UGM. 